\title{
Correction to: Artificial Neural Network Based Mission Planning Mechanism for Spacecraft
}

\author{
Zhaoyu $\mathrm{Li}^{1,2} \cdot$ Rui $\mathrm{Xu}^{1,2} \cdot$ Pingyuan $\mathrm{Cui}^{1,2}$. Shengying $\mathrm{Zhu}^{1,2}$
}

Published online: 21 June 2018

(c) The Korean Society for Aeronautical \& Space Sciences and Springer Nature Singapore Pte Ltd. 2018

\section{Correction to: International Journal of Aeronautical and \\ Space Sciences (2018) 19:111-119 \\ https://doi.org/10.1007/s42405-018-0006-6}

The original version of this article unfortunately contained a mistake. The information regarding the authors' affiliations was incorrect. The correct information is given below:

\footnotetext{
Zhaoyu $\mathrm{Li}^{1,2} \cdot$ Rui $\mathrm{Xu}^{1,2} \cdot$ Pingyuan $\mathrm{Cui}^{1,2} \cdot$ Shengying $\mathrm{Zhu}^{1,2}$
}

${ }^{1}$ School of Aerospace Engineering, Beijing Institute of Technology, Beijing, 100081, China

${ }^{2}$ Key Laboratory of Autonomous Navigation and Control for Deep Space Exploration, Ministry of Industry and Information Technology, Beijing, 100081, China

The original article can be found online at https://doi.org/10.1007/ s42405-018-0006-6.

Rui Xu

xurui@bit.edu.cn

1 School of Aerospace Engineering, Beijing Institute of Technology, Beijing 100081, China

2 Key Laboratory of Autonomous Navigation and Control for Deep Space Exploration, Ministry of Industry and Information Technology, Beijing 100081, China 